\title{
Antimicrobial activity and toxicity of Syzygium australe and Syzygium leuhmannii fruit extracts
}

\author{
C. Sautron ${ }^{\mathrm{a}}$, I.E. Cock ${ }^{\mathrm{b}, \mathrm{c}^{*}}$ \\ ${ }^{a}$ Ecole Supérieure d'Ingénieurs en Développement Agroalimentaire Intégré, Université de la Réunion, Parc Technologique, 2 rue Joseph \\ Wetzell, 27490 Sainte Clotilde, Ile de La Réunion \\ ${ }^{b}$ Environmental Futures Centre, Nathan Campus, Griffith University, 170 Kessels Rd, Nathan, Brisbane, Queensland 4111, Australia \\ 'Biomolecular and Physical Sciences, Nathan Campus, Griffith University, 170 Kessels Rd, Nathan, Brisbane, Queensland 4111, Australia
}

\begin{abstract}
Introduction: Many species of Syzygium are known to have antiseptic activity. Several Australian Syzygium species had roles as traditional bush medicines for Australian Aborigines although their antiseptic potential has not been rigorously studied. Methods: The antimicrobial activity of solvent extracts of Syzygium australe and Syzygium leuhmannii fruits were investigated by disc diffusion assay against a panel of bacteria and fungi and their MIC values were determined. Toxicity was determined using the Artemia franciscana nauplii bioassay. Results: The methanolic extracts of the fruit of both Syzygium species displayed the greater antibacterial activity of the extracts tested. S. australe generally had greater efficacy than the S. leuhmannii extracts. S. australe and $S$. leuhmannii fruit methanolic extract inhibited the growth of 13 (93\%) and 12 (86\%) of the 14 bacteria tested. Gram-positive and Gram-negative bacteria were both susceptible, although a slightly greater susceptibility of Gram-positive bacteria was noted. Nine (90\%) and $8(80 \%)$ of the $10 \mathrm{Gram}$-negative bacteria had their growth inhibited by $S$. australe and $S$. leuhmannii fruit methanolic extract extracts respectively. In contrast, methanolic extracts of both species inhibited growth of $100 \%$ of the Gram-positive bacteria tested. None of the extracts displayed broad antifungal activity. Indeed, none of the extracts inhibited the growth of $A$. niger or C. albicans. Only $S$. cerevisiae growth was affected and then only by the chloroform and hexane extracts. The methanolic, aqueous and ethyl acetate extracts of both Syzygium species were toxic in the Artemia franciscana bioassay, inducing significant mortality at $<1000 \mu \mathrm{g} / \mathrm{ml}$. Conclusions: The inhibitory bioactivity of $S$. australe against the bacterial panel validate Australian Aboriginal usage of $S$. australe leaves as antiseptic agents and confirms their medicinal potential, although care is needed in the uses of these extracts for these purposes due to their reported toxicity.
\end{abstract}

KEYWORDS: Syzygium australe, Syzygium leuhmannii, Australian plants, antibacterial activity, medicinal plants, toxicity

\section{INTRODUCTION}

Plants have long been used as medicines for treating a variety of different diseases and complaints. In many parts of the world plant preparations and medications continue to be used in the treatment of numerous disorders including eczema, malaria, respiratory disorders and infectious diseases. ${ }^{[1]}$ Plant based medicines have a

${ }^{*}$ Correspondence

I. E. Cock

Tel.: +61 737357637 ; fax: +61 737355282 .

E-mail address: I.Cock@griffith.edu.au

DOI: $10.5530 / p c .2014 .1 .8$ long history for the treatment of microbial infections in many traditional medicinal systems. For some of these plant treatments, antimicrobial activity has been proven. However, for many plant based antiseptics the evidence is anecdotal, or at best, epidemiological. Many traditionally used antiseptic agents have yet to be subjected to rigorous scientific investigation.

Syzygium is a large genus of evergreen flowering plants of the family Myrtaceae which consists of approximately 500 species. ${ }^{[2]}$ Plants of this genus are widespread, occurring in tropical and subtropical regions of South-East Asia, Australia and Africa. ${ }^{[3]}$ Many Syzygium species produce edible fruits and berries (eg. Syzygium jambos, commonly known as rose apple). In the commercially 
most important species Syzygium aromaticum (clove), the unopened flower bud is used as a spice. This plant also has uses in traditional medicine due to its anaesthetic properties. ${ }^{[4]}$ The antibacterial activity of $S$. aromaticum is also well known. Numerous studies have reported on the antibacterial ${ }^{[5]}$ and antifungal ${ }^{[6]}$ activities of oils and extracts from this plant. Other Syzygium species from South East Asia (Syzygium jambos) ${ }^{[7]}$ and India (Syzygium lineare and Syzygium cumini $)^{[8]}$ have also been shown to have antimicrobial activity. Much of our knowledge about the antimicrobial activities of Australian Syzygium species is anecdotal, although Australian Aborigines are known to have used some species as medicinal agents. ${ }^{[9]}$

Recent studies within our laboratory have reported antibacterial activity in several Australia Syzygium several species. ${ }^{[10-12]}$ In particular, Syzygium australe (Bush Cherry) and Syzygium leuhmannii (Riberry) extracts have been highlighted as having particularly good antimicrobial potential. ${ }^{[10,11]}$ However, these previous studies have examined leaf extracts only, without reporting on the medicinal potential of the fruit. Recent studies have also demonstrated the exceptionally high antioxidant content of fruits of these plants. ${ }^{[13]}$ Antioxidants have been associated with the prevention of cancer, cardiovascular disease and neurological degenerative disorders. ${ }^{[14-16]}$ They are also linked with antidiabetic bioactivities and have been associated with the reduction of obesity. Antioxidants can directly scavenge free radicals, protecting cells against oxidative stress related damage to proteins, lipids and nucleic acids. ${ }^{[17]}$ Therefore, T. lanceolata has potential in the treatment of a variety of diseases and disorders and its potential bioactivities warrant further investigation. The current study was undertaken to examine the antiseptic potential of $S$. australe and $S$. leubmannii fruit extracts of against a panel of bacteria and fungi and examine their toxicity to determine their suitability for use as antibiotic medicinal agents.

\section{MATERIALS AND METHODS}

\section{Plant material}

\section{Collection of plant samples}

S. australe and $S$. leubmannii fruit were collected from verified trees in the suburbs of Brisbane, Australia and voucher specimens were deposited in the School of Biomolecular and Physical sciences, Griffith University, Australia.

\section{Preparation of crude extracts}

Samples were dried in a Sunbeam food dehydrator and the dried material was ground to a coarse powder. An amount of $1 \mathrm{~g}$ of each of the powdered samples was extracted extensively in $50 \mathrm{ml}$ of either methanol, deionised water, ethyl acetate, chloroform or hexane respectively for 24 hours at $4^{\circ} \mathrm{C}$ with gentle shaking. All solvents were obtained from Ajax Australia and were of AR grade. The extracts were filtered through filter paper (Whatman No. 54) under vacuum followed by drying by rotary evaporation in an Eppendorf concentrator 5301. The resultant pellet was dissolved in $10 \mathrm{ml}$ of deionised water. The extract was passed through $0.22 \mu \mathrm{m}$ filter (Sarstedt) and stored at $4^{\circ} \mathrm{C}$.

\section{Qualitative phytochemical studies}

Phytochemical analysis of the Syzygium extracts for the presence of saponins, phenolic compounds, flavonoids, polysteroids, triterpenoids, cardiac glycosides, anthraquinones, tannins and alkaloids was conducted by previously described assays. ${ }^{[18-20]}$

\section{Antibacterial screening}

\section{Test microorganisms}

All media was supplied by Oxoid Ltd. Microbial strains were obtained from Tarita Morais, Griffith University. Stock cultures of Aeromonas hydrophilia, Alcaligenes feacalis, Bacillus cereus, Bacillus subtilis, Citrobacter freundii, Enterobacter aerogenes, Escherichia coli, Klebsiella pneumoniae, Pseudomonas aeuroginosa, Pseudomonas fuorescens, Salmonella salford, Serratia marcescens, Staphylococcus aureus and Yersinia enterocolitia were subcultured and maintained in nutrient broth at $4^{\circ} \mathrm{C}$. Aspergillus niger, Candida albicans, and Saccharomyces cerevisiae were maintained in Sabouraud media at $4^{\circ} \mathrm{C}$.

\section{Evaluation of antimicrobial activity}

Antimicrobial activity of all plant extracts was determined using a modified disc diffusion assay. ${ }^{[21-24]}$ Briefly, $100 \mu \mathrm{l}$ of the test bacteria were grown in $10 \mathrm{ml}$ of fresh media until they reached a count of approximately $10^{8}$ cells $/ \mathrm{ml}$. $100 \mu \mathrm{l}$ of microbial suspension was spread onto nutrient agar plates.

The Syzygium fruit extracts components were diluted to $10 \mathrm{mg} / \mathrm{ml}$ with deionised water and tested for antibacterial activity using $5 \mathrm{~mm}$ sterilised filter paper discs. Discs were impregnated with $10 \mu \mathrm{l}(100 \mu \mathrm{g})$ of the test sample, allowed to dry and placed onto inoculated plates. The plates were allowed to stand at $4^{\circ} \mathrm{C}$ for 2 hours 
before incubation with the test microbial agents. Plates inoculated with Alcaligenes feacalis, Aeromonas bydrophilia, Bacillus cereus, Citrobacter freundii, Klebsiella pneumoniae, Proteus mirabilis, Pseudomonas fluorescens, Serratia marcescens, were incubated at $30^{\circ} \mathrm{C}$ for 24 hours, then the diameters of the inhibition zones were measured in millimetres. Plates inoculated with Escherichia coli, Salmonella newport, Shigella sonnei, Staphylococcus aureus, Staphylococcus epidermidis and Streptococcus pyogenes were incubated at $37^{\circ} \mathrm{C}$ for 24 hours, then the diameters of the inhibition zones were measured. All measurements were to the closest whole millimetre. Each antimicrobial assay was performed in at least triplicate. Mean values $( \pm$ SEM) are reported in this study. Standard discs of ampicillin $(2 \mu \mathrm{g})$ and chloramphenicol $(10 \mu \mathrm{g})$ were obtained from Oxoid Ltd. and served as positive controls for antimicrobial activity. Filter discs impregnated with $10 \mu \mathrm{l}$ of distilled water were used as a negative control.

\section{Minimum inbibitory concentration (MIC) determination}

The minimum inhibitory concentration (MIC) of the Syzygium extracts were determined as previously described. ${ }^{[25]}$ Briefly, the plant extracts were diluted in deionised water and tested across a range of concentrations. Discs were impregnated with $10 \mu \mathrm{l}$ of the test dilutions, allowed to dry and placed onto inoculated plates. The assay was performed as outlined above and graphs of the zone of inhibition versus concentration were plotted for each extract. Linear regression was used to calculate the MIC values.

\section{Toxicity screening}

\section{Reference toxins for toxicity screening}

Potassium dichromate $\left(\mathrm{K}_{2} \mathrm{Cr}_{2} \mathrm{O}_{7}\right)$ (AR grade, ChemSupply, Australia) was prepared as a $1.6 \mathrm{mg} / \mathrm{ml} \mathrm{solu-}$ tion in distilled water and was serially diluted in artificial seawater for use in the Artemia franciscana nauplii bioassay.

\section{Artemia franciscana nauplii toxicity screening}

Toxicity was tested using a modified Artemia franciscana nauplii lethality assay. ${ }^{[26-29]}$ Briefly, $400 \mu$ of seawater containing approximately 48 (mean $47.8, \mathrm{n}=125, \mathrm{SD} 17.4$ ) A. franciscana nauplii were added to wells of a 48 well plate and immediately used for bioassay. $400 \mu$ l of diluted plant extracts and the reference toxins were transferred to the wells and incubated at $25 \pm 1^{\circ} \mathrm{C}$ under artificial light (1000 Lux). A negative control (400 $\mu \mathrm{l}$ seawater) was run in at least triplicate for each plate. All treatments were performed in at least triplicate. The wells were checked at regular intervals and the number of dead counted. The nauplii were considered dead if no movement of the appendages was observed within 10 seconds. After $72 \mathrm{~h}$ all nauplii were sacrificed and counted to determine the total $\%$ mortality per well. The $\mathrm{LC}_{50}$ with $95 \%$ confidence limits for each treatment was calculated using probit analysis.

\section{RESULTS}

\section{Liquid extraction yields and qualitative phytochemical screening}

Extraction of $1 \mathrm{~g}$ of dried plant material from each species yielded dried plant extracts ranging from $62 \mathrm{mg}$ to $442 \mathrm{mg}$ (Table 1). The greatest amount of material (442 mg) was extracted from S. leubmannii water extract. In general, the polar methanolic and aqueous solvents extracted the highest amounts of material, indicating the relatively high levels of polar compounds in the fruits of both species. Interestingly, the nonpolar chloroform extracts of both species also had high amounts of extracted material. The dried extracts were resuspended in $10 \mathrm{ml}$ of deionised water, resulting in the extract concentrations shown in Table 1.

Phytochemical studies (Table 1) show that the methanolic and aqueous extracts prepared from fruits of both species contained high levels of water soluble phenolic phytochemicals. The ethyl acetate extracts of both species also contained moderate to high levels of water soluble extracts. Whilst the ethyl acetate extracts of fruits of both species also had detectable levels of water insoluble phenolics, these were detected only at low levels. The methanolic, aqueous and the ethyl acetate extracts of both species also showed low to moderate responses for flavonoids and saponins. Moderate levels of polysteroids and low to moderate levels of triterpenoids were also detected in the methanolic and aqueous extracts. Neither alkaloids nor anthraquinones were detected in any extract tested. Similarly, tannins were largely lacking, with only the S. leubmannii methanol extract displaying any tannins, albeit only with a low response in this assay. Also noteworthy is the lack of detectable levels of any of the phytochemical classes tested for in the chloroform extracts of both species despite the large amounts of extracted material in these extracts. Chloroform would be expected to extract large amounts of lipids. The current study did not test for lipid levels so it is possible that much of this extracted material may consist of lipids, hydrocarbons and other nonpolar compounds. 
Table 1: The mass of dried extracted material, the concentration of extracts after resuspension in deionised water and qualitative phytochemical screenings of $S$. australe and S. leuhmannii extractions

\begin{tabular}{|c|c|c|c|c|c|c|c|c|c|c|c|c|c|c|c|c|}
\hline 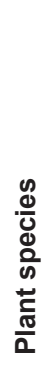 & 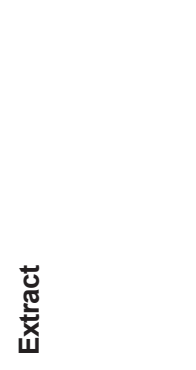 & 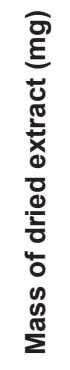 & 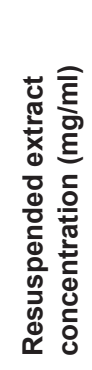 & 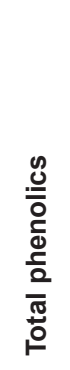 & 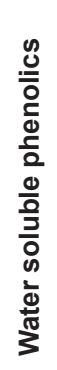 & 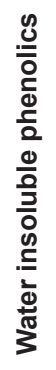 & 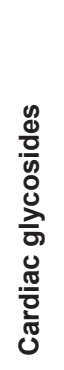 & 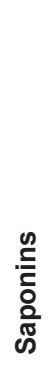 & 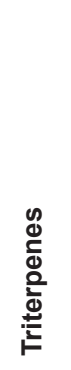 & 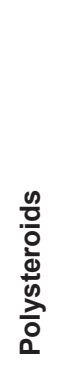 & 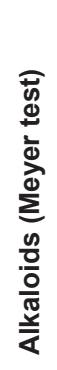 & 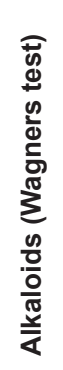 & $\begin{array}{l}\frac{0}{0} \\
\frac{0}{0} \\
\frac{\pi}{\pi} \\
\frac{\pi}{L} \\
\frac{\pi}{L}\end{array}$ & 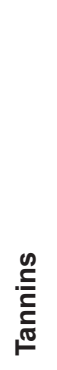 & 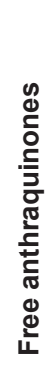 & 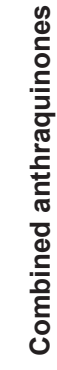 \\
\hline \multirow{5}{*}{ 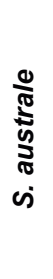 } & Methanol & 254 & 25.4 & +++ & ++ & - & ++ & - & + & ++ & - & - & + & - & - & - \\
\hline & Water & 200 & 20 & +++ & ++ & - & - & + & - & ++ & - & - & ++ & - & - & - \\
\hline & Ethyl Acetate & 87 & 8.7 & ++ & + & + & - & + & - & - & - & - & ++ & - & - & - \\
\hline & Chloroform & 247 & 24.7 & + & - & + & + & - & - & - & - & - & - & - & - & - \\
\hline & Hexane & 62 & 6.2 & - & - & - & - & + & - & - & - & - & - & - & - & - \\
\hline \multirow{5}{*}{ 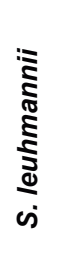 } & Methanol & 427 & 42.7 & +++ & ++ & - & - & + & + & ++ & - & - & ++ & + & - & - \\
\hline & Water & 442 & 44.2 & +++ & ++ & - & - & + & ++ & ++ & - & - & ++ & - & - & - \\
\hline & Ethyl Acetate & 84 & 8.4 & ++ & + & - & - & + & - & - & - & - & + & - & - & - \\
\hline & Chloroform & 382 & 38.2 & + & - & - & - & - & - & - & - & - & + & - & - & - \\
\hline & Hexane & 83 & 8.3 & - & - & - & - & + & - & - & - & - & - & - & - & - \\
\hline
\end{tabular}

+++ indicates a large response $;++$ indicates a moderate response $;$ + indicates a minor response; - indicates no response in the assay.

\section{Antibacterial activity}

The Syzygium fruit extracts were tested for antimicrobial activity at the extracted concentrations (Table 1) in the disc diffusion assay against 14 bacterial and 3 fungal species (Figure 1). S. australe extracts were generally more effective antimicrobial agents than the S. leubmannii extracts in terms of the diversity of the bacteria inhibited and the size of the zones of inhibition. In general, the polar methanol, water and ethyl acetate extracts had greater antimicrobial activity than the nonpolar chloroform and hexane extracts. Indeed, of the 14 bacterial species tested, the $S$. australe and S. leubmannii methanolic extracts inhibited the growth of $13(93 \%)$ and $12(86 \%)$ bacterial species respectively. The water, ethyl acetate, chloroform and hexane extracts were less effective, with the $S$. australe water, ethyl acetate, chloroform and hexane extracts inhibiting the growth of 7 (50\%), 9 (64\%), 4 $(29 \%)$ and $4(29 \%)$ of the 14 bacteria tested respectively. The $S$. leubmannii water, ethyl acetate, chloroform and hexane extracts had similar antibacterial profiles, inhibiting the growth of $5(36 \%), 9(64 \%), 4(29 \%)$ and 3 $(21 \%)$ of the 14 bacteria tested respectively.

Both Gram-positive and Gram-negative bacteria were affected by the methanolic fruit extracts although the Gram-positive bacteria appeared slightly more susceptible to the extracts of most of the Syzygium extracts tested (based on the number of species whose growth was inhibited). Of the $10 \mathrm{Gram}$-negative bacteria tested, the $S$. australe and $S$. leubmannii methanolic extracts inhibited 9 bacteria $(90 \%)$ and $8(80 \%)$ respectively. In contrast, the $S$. australe and $S$. leubmannii methanolic extracts both inhibited 4 of the 4 Gram-positive bacteria tested $(100 \%)$.

The relative antibacterial activity strength of the extracts was evaluated by determining the MIC values for each extract against the bacteria which were shown to be susceptible by disc diffusion assays. MIC's were evaluated in the current studies across a range of concentrations. This has previously been determined to be a valid method of MIC determination as MIC values determined by disc diffusion correlate well with those determined by broth dilution assays. ${ }^{[30]}$ The antibacterial activity was generally strongest against Gram-positive bacteria with the MIC's for several extracts against several bacterial species below $1 \mathrm{mg} / \mathrm{ml}$ (Table 2). The S. leubmannii ethyl acetate extract in particular was a good inhibitor of the Gram-positive bacillus B. cereus (MIC $0.1 \mathrm{mg} / \mathrm{ml}$ ) and the Gram-negative bacteria S. sonnei (MIC $0.7 \mathrm{mg} / \mathrm{ml}$ ). 

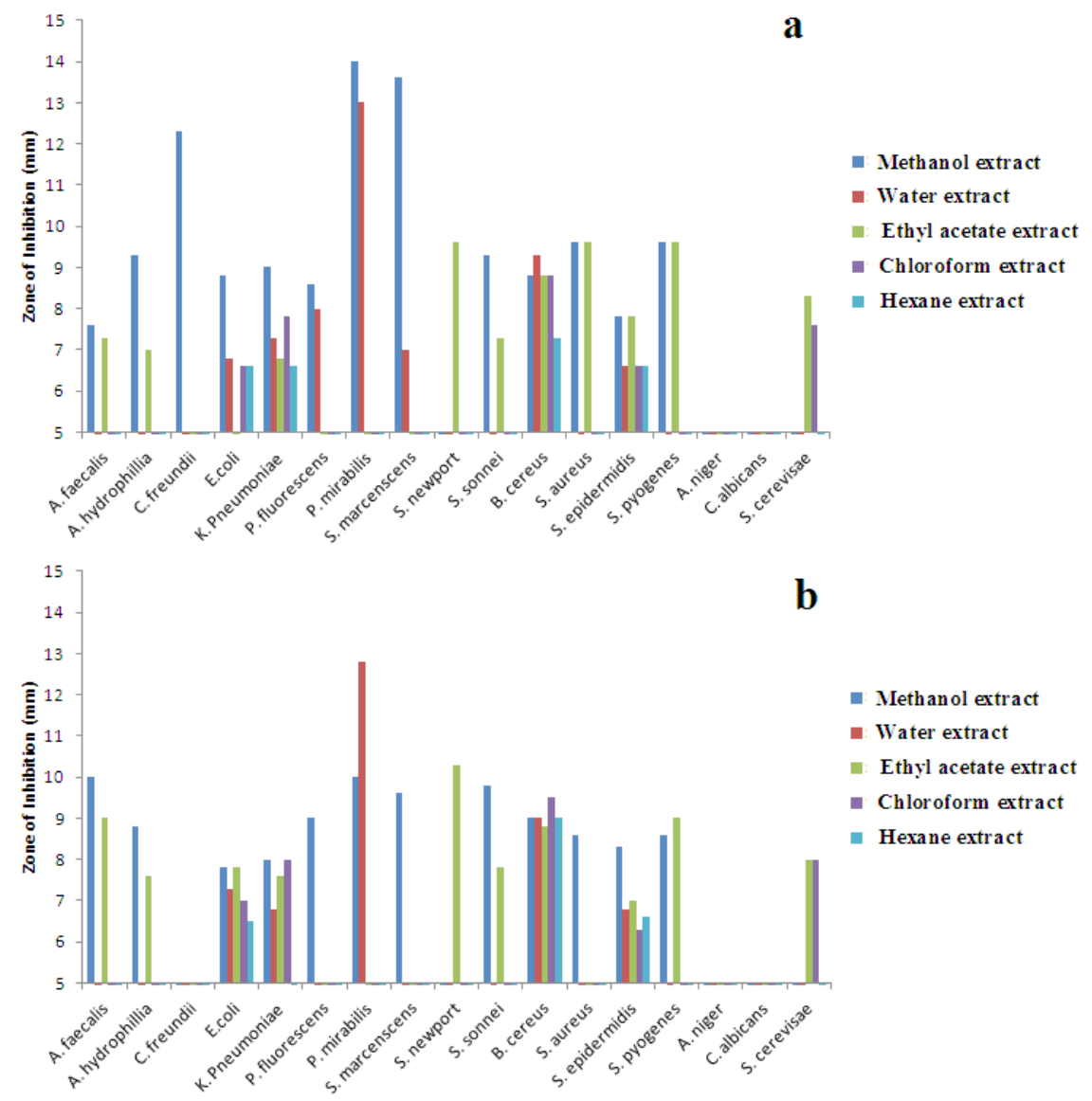

Figure 1. Antimicrobial activity measured as zones of inhibition (mm) of (a) Syzygium australe and (b) S. leubmannii. Inhibition zones are represented as the means of at least triplicate experiments.

Table 2: Minimum inhibitory concentrations $(\mathrm{mg} / \mathrm{ml})$ of $S$. australe and $S$. leuhmannii fruit extracts against susceptible bacterial and fungal species

\begin{tabular}{|c|c|c|c|c|c|c|c|c|c|c|c|c|c|c|c|c|}
\hline 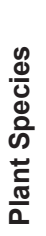 & 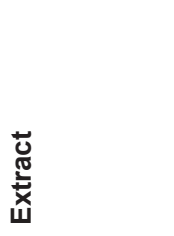 & 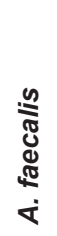 & 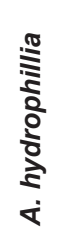 & 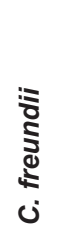 & $\begin{array}{l}\text { ¿े } \\
\text { ư }\end{array}$ & 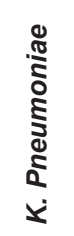 & 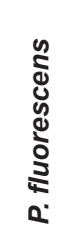 & 查 & 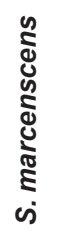 & 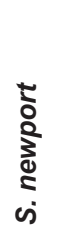 & 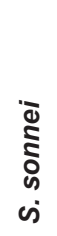 & 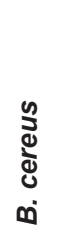 & 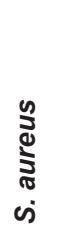 & 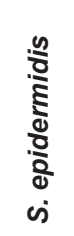 & 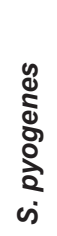 & 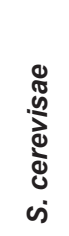 \\
\hline \multirow{5}{*}{ 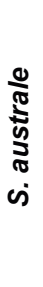 } & Methanol & 2.9 & 2.7 & 1.7 & 2.6 & 3.8 & 2.1 & 0.2 & 3.3 & - & 2.6 & 2.3 & 0.8 & 5.4 & 0.8 & - \\
\hline & Water & - & - & - & 20 & 10 & 10 & - & 1.3 & - & - & 1.9 & - & 20 & - & - \\
\hline & $\begin{array}{l}\text { Ethyl } \\
\text { Acetate }\end{array}$ & 8.7 & 4.3 & - & - & 1 & - & - & - & 0.5 & - & - & - & - & 0.8 & 1.7 \\
\hline & Chloroform & - & - & - & 24.7 & 24.7 & - & - & - & - & - & 0.4 & - & 24.7 & - & 12.3 \\
\hline & Hexane & - & - & - & 6.3 & 3.1 & - & - & - & - & - & 3.1 & - & 6.2 & - & - \\
\hline \multirow{5}{*}{ 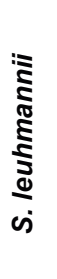 } & Methanol & 6.6 & 3.6 & - & 2.5 & 0.1 & 3.7 & 2.9 & 2.2 & - & 4.9 & 3.3 & 1.9 & 1.2 & 2.5 & - \\
\hline & Water & - & - & - & 44.2 & 44.2 & - & 4.7 & 7 & - & - & 5.5 & - & 44.2 & - & - \\
\hline & $\begin{array}{l}\text { Ethyl } \\
\text { Acetate }\end{array}$ & 1.1 & 4.2 & - & 0.8 & 4.2 & - & - & - & 1.4 & 0.7 & 0.1 & - & 4.2 & 1.3 & 4.2 \\
\hline & Chloroform & - & - & - & 38.2 & 38.2 & - & - & - & - & - & 2.6 & - & 38.2 & - & 7.6 \\
\hline & Hexane & - & - & - & 6.2 & - & - & - & - & - & - & 1 & - & 8.3 & - & - \\
\hline
\end{tabular}

Numbers indicate the mean MIC values of at least triplicate determinations. - indicates no growth inhibition observed. 
In contrast with their antibacterial activities, the $S$. australe and $S$. leubmannii fruit extracts were poor inhibitors of fungal growth. Neither $A$. niger nor $C$. albicans growth were inhibited by any of the extracts tested. Only $S$. cerevisae growth was affected and only by the ethyl acetate and chloroform extracts of both species (Figure 1 and Table 2).

\section{Qantification of toxitity}

The Syzygium fruit extracts were diluted to $4000 \mu \mathrm{g} /$ $\mathrm{ml}$ in artificial seawater for toxicity testing, resulting in a $2000 \mu \mathrm{g} / \mathrm{ml}$ concentration in the Artemia franciscana lethality bioassay. For comparison, the reference toxins potassium dichromate $(800 \mu \mathrm{g} / \mathrm{ml})$ was also tested in the Artemia franciscana lethality bioassay. For the reference toxins, the induction of mortality was seen within the first 4 hours of exposure. 100\% mortality was evident following 8 hours of exposure (results not shown). In contrast, 12 hours was required for the Syzygium fruit extracts to induce the onset of mortality. By $24 \mathrm{~h}$ exposure, the methanolic, water and ethyl acetate extracts of both species had induced $100 \%$ brine shrimp mortality. The chloroform and hexane extracts were less toxic, inducing only low levels of mortality similar to that seen for the seawater control at 24 hours. The levels of mortality induction had increased by 48 hours for the $S$. leubmanni chloroform and hexane extracts, with these levels approaching 100\% mortality induction by 72 hours of exposure. In contrast, the S. australe chloroform and hexane extracts induced only relatively low mortality for the entire 72 hours exposure period.

To further quantify the effect of toxin concentration on the induction of mortality, the extract was serially diluted in artificial seawater to test across the concentration range $2000 \mu \mathrm{g} / \mathrm{ml}$ to $15 \mu \mathrm{g} / \mathrm{ml}$ in the Artemia nauplii bioassay at 24, 48 and 72 hours. Table 3 shows the LC $_{50}$ values of the Syzygium fruit extracts towards $A$. franciscana. No $\mathrm{LC}_{50}$ values are reported for the $S$. australe chloroform and hexane fruit extracts at any time, nor for the S. leubmannii hexane fruit extract at $24 \mathrm{~h}$ as less than $50 \%$ mortality was seen for all concentrations tested at these time points. Furthermore, the $S$. leubmannii chloroform and hexane fruit extracts displayed low toxicity (generally $>1000 \mu \mathrm{g} / \mathrm{ml}$ ) at all times tested and are therefore considered to be nontoxic. All other extracts tested displayed significant toxicity.

\section{DISCUSSION}

The current study reports on the antimicrobial activity and toxicity of fruit extracts of $S$. australe and $S$. leubmannii. The ability of the leaf extracts to inhibit

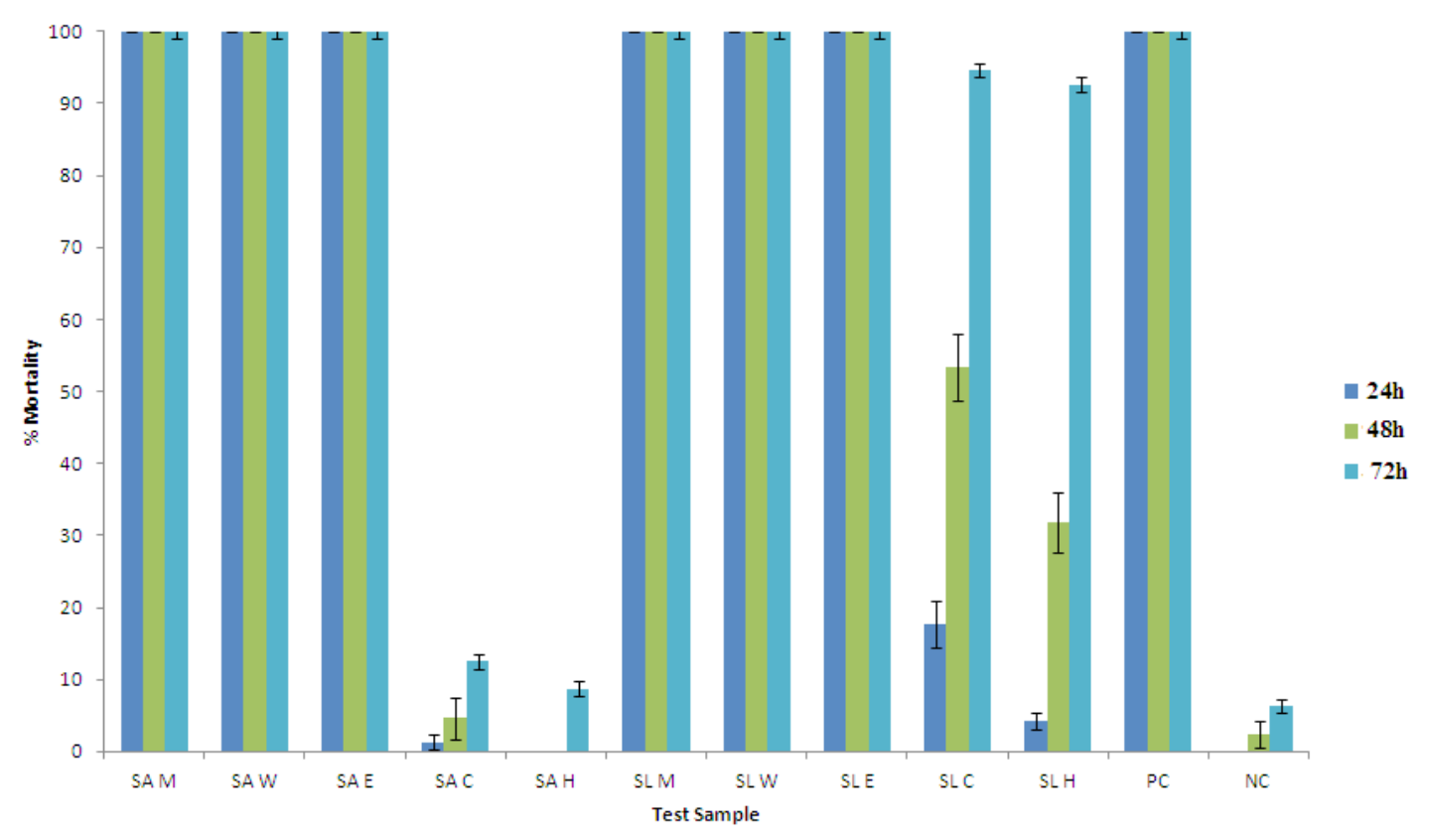

Figure 2. Brine shrimp lethality of $S$. australe and $S$. leubmannii fruit extracts (tested at $2000 \mu \mathrm{g} / \mathrm{ml}$ ), and the potassium dichromate $(800 \mu \mathrm{g} / \mathrm{ml})$ and seawater controls. SAM $=S$. australe methanolic extract; SAW $=S$. australe water extract; SAE $=S$. australe ethyl acetate extract; SAC $=S$. australe chloroform extract; $\mathrm{SAH}=S$. australe hexane extract; SLM $=$ S. leubmannii methanolic extract; SLW $=S$. leubmannii water extract; SLE $=S$. leubmannii ethyl acetate extract; SLC $=S$. leubmannii chloroform extract; SLH $=$ $S$. leuhmannii hexane extract. All bioassays were performed in at least triplicate and are expressed as mean \pm SEM. 


\begin{tabular}{|c|c|c|c|c|}
\hline \multirow{2}{*}{$\begin{array}{l}\text { Plant } \\
\text { Species }\end{array}$} & \multicolumn{4}{|c|}{$\mathrm{LC}_{50}(\mu \mathrm{g} / \mathrm{ml})$ at time $(\mathrm{h})$} \\
\hline & Extract & $24 \mathrm{~h}$ & $48 \mathrm{~h}$ & $72 \mathrm{~h}$ \\
\hline \multirow{6}{*}{ 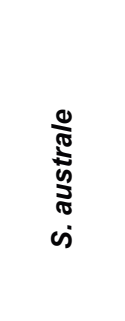 } & Methanol & 294 & 257 & 246 \\
\hline & Water & 244 & 231 & 231 \\
\hline & Ethyl Acetate & 514 & 416 & 339 \\
\hline & Chloroform & - & - & - \\
\hline & Hexane & - & - & - \\
\hline & Methanol & 414 & 314 & 252 \\
\hline \multirow{4}{*}{ 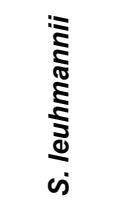 } & Water & 478 & 472 & 472 \\
\hline & Ethyl Acetate & 181 & 143 & 120 \\
\hline & Chloroform & 4149 & 1857 & 990 \\
\hline & Hexane & - & 2632 & 1487 \\
\hline \multicolumn{2}{|c|}{ Potassium Dichromate } & 233 & 38 & 18 \\
\hline
\end{tabular}

- denotes values that were not obtained as $\geq 50 \%$ mortality was not obtained at this time point.

the growth of both Gram-positive and Gram-negative bacteria is in agreement with previous reports of the antibacterial activity of other Syzygium spp. ${ }^{[10,31-33]}$ The greater susceptibility of Gram-positive bacteria seen in this study agrees with the previously reported specificities of South American, ${ }^{[34]}$ African ${ }^{[35]}$ and Australian ${ }^{[36]}$ plant extracts. Results within this laboratory have also confirmed the greater susceptibility of Gram-positive bacteria towards other Australian plant extracts. ${ }^{[10,37]}$ The Gram-negative bacterial cell wall outer membrane is thought to act as a barrier to many substances including antibiotics. ${ }^{[38]}$ The uptake of the Syzygium extract antibiotic agents by Gram-negative bacteria may be affected by the cell wall outer membrane of some bacteria. Individual Syzygium leaf components responsible for the antisceptic potential of the Syzygium leaf extracts were not identified in the current study. Further phytochemical studies are needed to purify and identify the antibacterial components from these extracts.

The findings reported here also indicate that the majority of the Syzygium extracts examined in this study displayed significant toxicity $(<1000 \mu \mathrm{g} / \mathrm{ml})$ in the Artemia nauplii bioassay. This toxicity would impact on the usefulness of these extracts as a medicinal antiseptic agent. Similar extracts prepared from fruits of these species have previously been reported to have high ascorbic acid levels. ${ }^{[13]}$ Whilst these ascorbic acid levels may have beneficial therapeutic effects, they may also be responsible (at least in part) for the toxicity reported here. Whilst
A. franciscana have generally been reported to be a robust and hardy organism for toxicity screening, they are susceptible to $\mathrm{pH}$ changes. ${ }^{[40]}$ The levels of ascorbic acid previously reported in $S$. australe and $S$. leubmannii extracts ${ }^{[13]}$ would be expected to have a significant impact on the $\mathrm{pH}$ of the seawater in the tests and this change may be responsible for the mortality induction reported in our study. Indeed, studies in our laboratory have shown that testing pure ascorbic acid in the concentrations previously reported to be in these extracts results in mortality similar to that reported in our study (unpublished results).

Whilst toxicity was assessed in this study with the test organism A. franciscana, toxicity towards $A$. franciscana has previously been shown to correlate well with toxicity towards human cells for many toxins. ${ }^{[39]}$ However, further studies are required to determine whether this is also true for the Syzygium extracts examined in these studies. Toxic antibacterial extracts may still be useful as non-medicinal antibacterial agents (eg. surface disinfectants and topical antiseptics). Likewise, toxic plant extracts may also still have medicinal potential even if they are not antimicrobial. Previous studies have demonstrated that toxicity in the $A$. franciscana bioassay may indicate anti-cancer potential. ${ }^{[39]}$ The toxic Syzygium fruit extracts should therefore also be tested against human cancer cell lines to determine their potential as anticancer drugs.

In conclusion, the results of this study indicate that the Syzygium leaf extracts examined in this report are worthy of further study due to their antibacterial activity. Conversely, the toxicity detected for these extracts indicates that further toxicity studies are required to evaluate the safety of these extracts for medicinal usage. Further evaluation of the antibacterial properties of these extracts against a more extensive panel of microbial agents is also warranted. Likewise, purification and identification of the bioactive components is needed to examine the mechanisms of action of these agents. Whilst the extracts examined in this report have potential as antimicrobial agents, caution is needed before these compounds can be applied to medicinal purposes. In particular, further toxicity studies using human cell lines are needed to determine the suitability of these extracts for these purposes.

\section{ACKNOWLEDGEMENTS}

Financial support for this work was provided by the School of Biomolecular and Physical Sciences, Griffith University, Australia. 


\section{REFERENCES}

1. Hoareau L, DaSilva EJ. Medicinal plants: a re-emerging health aid, Electronic Journal of Biotechnology 1999; 2(2):56-70.

2. Page S, Olds M. Botanica : The Illustrated A - Z of Over 10,000 Garden Plants for Australian Gardens and How to Cultivate Them. Random House 2004; Australia.

3. Chandrasekaran M, Venkatesalu V. Antibacterial and antifungal activity of Syzygium jambolanum seeds. Journal of Ethnopharmacology 2004; 91:105-108.

4. Cai L, Wu CD. Compounds from Syzygium aromaticum possessing growth inhibitory activity against oral pathogens. Journal of Natural Products 1996; 59:987-990.

5. Arora DS, Kaur GJ. Antibacterial activity of some Indian medicinal plants. Journal of Natural Medicine 2007; 61:313-317.

6. Park MJ, Gwak KS, Yang I, Choi WS, Jo HJ, Chang JW, Jeung EB, Choi IG. Antifungal activities of the essential oils of Syzygium aromaticum (L.) Mer. Et Perry and Leptospermum petersonii Bailey and their constituents against various dermatophytes. Journal of Microbiology 2007; 45(5):60-465.

7. Mohanty S, Cock IE. Bioactivity of Syzygium jambos methanolic extracts: Antibacterial activity and toxicity. Pharmacognosy Research 2010; 2(1):4-9.

8. Duraipandiyan V, Ayyanar M Ignacimuthu S. Antimicrobial activity of some ethnomedicinal plants used by Paliyar tribe from Tamil Nadu, India. BMC Complimentary and Alternative Medicine 2006; 6(35):1-7.

9. Cock IE. Medicinal and aromatic plants - Australia, in Ethnopharmacology section, Biological, Physiological and Health Sciences, Encyclopedia of Life Support Systems (EOLSS), 2011; Developed under the Auspices of the UNESCO, EOLSS Publishers, Oxford ,UK, (http://www.eolss.net).

10. Cock IE. Antibacterial activity of selected Australian plant extracts. The Internet Journal of Microbiology 2008; 4, 2.

11. Cock IE. Antibacterial activity of Syzygium australe and Syzygium leuhmannii leaf methanolic extracts. Pharmacognosy Communications 2012; 2(2):71-77

12. Chikowe G, Mpala L, Cock IE. Antibacterial activity of selected Australian Syzygium species. Pharmacognosy Communications 2013; 3(4).

13. Netzel M, Netzel G, Tian Q, Schwartz S, Konczak I. Native Australian fruits - a novel source of antioxidants for food. Innov Food Sci Emerg Technol 2007; 8:339-46.

14. Potter JD. Cancer prevention: epidemiology and experiment. Cancer Lett 1997; 114:7-9.

15. Mohanty S, Cock IE. The chemotherapeutic potential of Terminalia ferdinandiana: Phytochemistry and bioactivity. Pharmacognosy Reviews 2012; 6(11):29-36.

16. Cock IE. Problems of reproducibility and efficacy of bioassays using crude extracts, with reference to Aloe vera. Pharmacognosy Communications 2011; 1(1):52-62.

17. Rice-Evans C, Miller N, Paganga. Antioxidant properties of phenolic compound. Trends Plant Sci 1997; 2(4):152-9.

18. Kukkonen L, Cock IE. An examination of the medicinal potential of Scaevola spinescens: Toxicity, antibacterial, and antiviral activities. Pharmacognosy Research 2011; 3(2):85-94.

19. Vesoul J, Cock IE. An examination of the medicinal potential of Pittosporum phylliraeoides: Toxicity, antibacterial, and anfungal activities. Pharmacognosy Communications 2011; 1(2):8-17.

20. Kalt FR, Cock IE. GC-MS analysis of bioactive Petalostigma extracts: toxicity, antibacterial and antiviral activities. Pharmacognosy Magazine 2013.
21. Cock IE. Antibacterial activity of Aloe barbadensis Miller leaf gel components. The Internet Journal of Microbiology 2008; 4, 2.

22. Cock IE. Antibacterial activity of Allocasuarina littoralis leaf gel components. The Internet Journal of Microbiology 2008; 5, 2.

23. Cock IE. Antimicrobial activity of Acacia aulacocarpa and Acacia complanta methanolic extracts. Pharmacognosy Communications 2012 2(1):66-71.

24. Mpala L, Chikowe G, Cock IE. No evidence of antiseptic properties and low toxicity of selected Aloe species. Journal of Pharmaceutical Negative Results 2010; 1(1) 10-16.

25. Mohanty S, Cock IE. Evaluation of the antibacterial activity of Myrciaria caulifloria methanolic leaf and fruit extracts. The Internet Journal of Microbiology 2009; 7, 2.

26. Cock IE, Ruebhart, DR. Assessment of the toxicity of selected Australian native plant extracts using the Artemia franciscana nauplii bioassay. The Internet Journal of Toxicology 2008; 5, 2 .

27. Cock IE, Ruebhart DR. Comparison of the brine shrimp nauplii bioassay and the ToxScreen-II test for the detection of toxicity associated with Aloe vera (Aloe barbadensis Miller) leaf extract. Pharmacognosy Research 2009; 1(2):102-108.

28. Sirdaarta J, Cock IE. Vitamin $\mathrm{E}$ and Trolox ${ }^{\mathrm{TM}}$ reduce toxicity of Aloe barbadensis Miller juice in Artemia franciscana nauplii but individually are toxic at high concentrations. The Internet Journal of Toxicology 2008; $5,1$.

29. Ruebhart DR, Wickramasinghe W, Cock IE. Protective efficacy of the antioxidants vitamin E and Trolox against Microcystis aeruginosa and microcystin-LR in Artemis franciscana nauplii. Journal of Toxicology and Environmental Health Part A 2009; 72:1567-1575.

30. Gaudreau C, Girouard Y, Ringuette L, Tsimiklis C. Comparison of disc diffusion and agar dilution methods for erythromycin and ciprofloxacin susceptibility testing of Campylobacter jejuni subsp. Jejuni. Antimicrobia Agents and Chemotherapy 2007; 1524-1526.

31. Arora DS, Kaur GJ. Antibacterial activity of some Indian medicinal plants, Journal of Natural Medicine 2007; 61:313-317.

32. Duraipandiyan V, Ayyanar M, Ignacimuthu S. Antimicrobial activity of some ethnomedicinal plants used by Paliyar tribe from Tamil Nadu, India. BMC Complimentary and Alternative Medicine 2006; 6: 35

33. Shafi PM, Rosamma MK, Jamil K, Reddy PS. Antibacterial activity of Syzygium cumini and Syzygium traancoricum leaf essential oils. Fitoterapia 2002; 73:414-416.

34. Paz EA, Cerdeiras MP, Fernandez J, Ferreira F, Moyna P, Soubes M, Vazquez A, Vero S, Zunino L. Screening of Uruguayan medicinal plants for antimicrobial activity. Journal of Ethnopharmacology 1995; 45:67-70.

35. Kudi AC, Umoh JU, Eduvie LO, Gefu J. Screening of some Nigerian medicinal plants for antibacterial activity. Journal of Ethnopharmacology 1999; 67:225-228.

36. Palombo EA, Semple SJ. Antibacterial activity of traditional Australian medicinal plants. Journal of Ethnopharmacology 2001; 77:151-157.

37. Cock IE. Antimicrobial activity of Eucalyptus major and Eucalyptus baileyana methanolic extracts. The Internet Journal of Microbiology 2009; $6,1$.

38. Tortora GJ, Funke BR, Case CL. Microbiology: An Introduction. 2001; Benjamin Cummings, San Francisco.

39. McLaughlin JL, Rogers LL, Anderson JE. The use of biological assays to evaluate botanicals. Drug Information Journal 1998; 32:513-524.

40. Cock IE, Ruebhart DR. Comparison of the brine shrimp naup[lii bioassay and the ToxScreen-II test for the detection of toxicity associated with Aloe vera (Aloe barbadensis Miller) leaf extracts. Pharmacognosy Research 2009; 1(2):98-101. 